\title{
Epidemiology of Systemic Lupus Erythematosus in Saudi Arabia
}

\author{
Mostafa A Abdel Maksoud*1,2 \\ ${ }^{1}$ Department of Zoology, College of Science, Saudi Arabia \\ ${ }^{2}$ Department of Zoology, Faculty of Science, Egypt
}

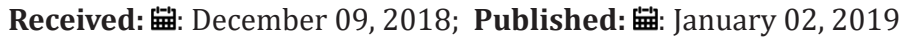

*Corresponding author: Mostafa A Abdel Maksoud, PhD in Immunology, Zoology Department, College of Science, Saudi Arabia

Abbreviation: SLE: Systemic Lupus Erythematosus, CKD: Chronic kidney Disease, ESRD: End Stage Renal Disease, LN:Lupus Nephritis, AI: Activity Index, ICU: Intensive Care Unit

\section{Introduction}

Systemic lupus erythematosus (SLE) is a multisystem autoimmune disease with unknown etiology and growing incidence both locally and globally [1-2]. Like other autoimmune diseases, SLE remains incurable despite the newly introduced category of therapeutic agents namely biological therapies which target interferons, cytokines, Tlymphocytes and co-stimulatory molecules, B-lymphocytes and B stimulatory molecules [3]. The prevalence data concerning any disease is crucial for the determination of its potentiality on the affected community. Generally, the prevalence data for SLE is not enough and still many areas around the world have lupic patients with no specific estimates for the disease prevalence rate while epidemiological data in other areas have been estimated many years before [4]. In Saudi Arabia, the first attempt was a study conducted to assess the incidence and clinical expression of SLE in the Eastern Province of Saudi Arabia and it revealed that the disease is uncommon in this region, only 32 cases being recorded in five years. However, the clinical manifestations of the disease are similar to those observed elsewhere [5]. In the Capital, Riyadh, another study was adjusted one year after the first one and the results were to large extent, similar [6]. A third study was conducted to determine the prevalence of SLE in Al-Qaseem region of the Kingdom of Saudi Arabia [7]. Later on, a retrospective study included patients who were diagnosed and treated for SLE from 1982 to 2008 at King Khalid University hospital, Riyadh was adjusted. Demographic and hematological parameters at diagnosis and the last follow-up, disease manifestations, organ involvement and clinical hematological complications were recorded. Association of hematological abnormalities with organ involvement was also explored [8]. Another retrospective study, which covered a 27 year period (1980-2006) was conducted where 624 SLE patients referring to King Khalid University hospital, Riyadh were included [9]. The outcomes of lupus on pregnant women were also considered by researchers in Saudi Arabia. In an eminent study, Pregnancy outcome in 396 pregnancies in patients with SLE in Saudi Arabia was investigated. a retrospective evaluation of all pregnancies occurring in patients with SLE during the period from 1980 to 2006 was done. They have concluded that it is important to carefully plan pregnancy, and experienced rheumatologists and obstetricians should monitor SLE patients in pregnancy and postpartum [10]. Viral infections can affect the lupic patients in a higher rate than normal individuals. An important study has concluded that Herpes Zoster infections occur at increased frequency among patients with SLE and carry significant morbidity. Immunosuppressive therapy and severe manifestations of lupus may be risk factors for the development of Herpes Zoster although not necessarily at the time of disease flare or immunosuppressive therapy [11]. Lupus nephritis is a major risk factor for overall morbidity and mortality in SLE, and despite potent anti-inflammatory and immunosuppressive therapies still ends in chronic kidney disease (CKD) or end stage renal disease (ESRD) for too many patients [12]. The prevalence, clinical features, WHO histological types, therapy and renal outcome of lupus nephritis (LN) in Saudi Arabian patients was investigated during the period (1980-2006) [13]. Tubuloreticular inclusions (TRIs) were detected in renal biopsies of Saudi lupic patients and their correlation with the activity index (AI) and lupus nephritis (LN) class were determined [14]. Racial differences 
between SLE patients were recorded in one study conducted in the western province whereas, Patients of African descent had higher rates of neurological involvement and renal failure. The mortality in this group was also highest [15]. The affected age in lupic patients was screened and studies done in eastern and central regions of the kingdom have shown that patients with SLE are found to be between the age group 20-30 [16,17]. The mortality rate between lupic patients is higher, mainly due to organ damage. Consequently, a cohort study was conducted and the causes, outcome and prognosis of severe illness in patients with SLE requiring intensive care unit (ICU) care in a University Hospital over a five-year period (January 1997-December 2001) were studied prospectively [18]. The relationship between SLE and infections is still mysterious with controversial data [19]. An important study has illustrated that more judicious use of corticosteroids and other immunosuppressive agents will be critical to limit the infections in SLE and a high alert and close monitoring of patients will ensure optimal patient outcome, both in terms of morbidity and mortality [20]. Complications of lupus on the cardiovascular [21] and pulmonary systems [22] were studied in two different studies in the western province. On the other hand, retrospective study aimed to collect data related to the clinical manifestations and laboratory investigations of SLE patients in the eastern part of Saudi Arabia was performed [23]. Indeed, the available data about the epidemiology of SLE in Saudi Arabia is suffering from a shortage in both of the southern and northern provinces while data from eastern, western and central areas are to some extent better with persistent need to more comprehensive studies.

\section{Conclusion}

Studies about SLE epidemiology in the Kingdom of Saudi Arabia are neither few nor adequate. It needs more attention from researchers to continuously update the new records for the disease so as to accurately determine its epidemiology.

\section{References}

1. Rees F, Doherty M, Grainge MJ, Lanyon P, Zhang W, et al. (2017) The worldwide incidence and prevalence of systemic lupus erythematosus: a systematic review of epidemiological studies. Rheumatology (Oxford) 56(11): 1945-1961.

2. Danchenko N, Satia JA, Anthony MS (2006) Epidemiology of systemic lupus erythematosus: a comparison of worldwide disease burden. Lupus 15(5): 308-318.

3. Bernal CB, Zamora LD, Navarra SV (2015) Biologic therapies in systemic lupus erythematosus. Int J Rheum Dis 18(2): 146-153.

4. Siegel M, Lee SL (1973) The epidemiology of systemic lupus erythematosus. Semin Arthritis Rheum 3(1): 1-54.

5. Al Nahdi MS, Al Mohaya S, Al Fadel Saleh M, Al Awamy BH, Abdulrahman IS. et al. (1987) Clinical presentation of systemic lupus erythematosus in Saudi patients. Trop Geogr Med 39(2): 187-190.
6. Al-Nasser AA, Aboul-Enein M el-S, Al-Aska AK (1988) Systemic lupus erythematosus in Riyadh, Saudi Arabia. J R Soc Health 108(3): 90-96.

7. Al-Arfaj AS, Al-Balla SR, Al-Dalaan AN, Al-Saleh SS, Bahabri SA, et al. (2002) Prevalence of systemic lupus erythematosus in central Saudi Arabia. Saudi Med J. 23(1): 87-89.

8. Aleem A, Al Arfaj AS, khalil N, Alarfaj H (2014) Haematological abnormalities in systemic lupus erythematosus. Acta Reumatol Port 39(3): 236-241.

9. Al Arfaj AS, Khalil N (2009) Clinical and immunological manifestations in 624 SLE patients in Saudi Arabia. Lupus 18(5): 465-473.

10. Al Arfaj AS, Khalil N (2010) Pregnancy outcome in 396 pregnancies in patients with SLE in Saudi Arabia. Lupus 19(14): 1665-1673.

11. Sayeeda A, Al Arfaj H, Khalil N, Al Arfaj AS (2010) Herpes Zoster Infections in SLE in a University Hospital in Saudi Arabia: Risk Factors and Outcomes. Autoimmune Dis 2011(13): 174891.

12. Almaani S, Meara A and. Rovin B (2017) Update on Lupus Nephritis. Clin J Am Soc Nephrol 12(5): 825-835.

13. Al Arfaj AS, Khalil N, Al Saleh S (2009) Lupus nephritis among 624 cases of systemic lupus erythematosus in Riyadh, Saudi Arabia. Rheumatol Int 29(9): 1057-1067.

14. Kfoury H (2014) Tubulo-reticular inclusions in lupus nephritis: are they relevant? Saudi J Kidney Dis Transpl 25(3): 539-543.

15. Heller T, Ahmed M, Siddiqqi A, Wallrauch C, Bahlas S, et al. (2007) Systemic lupus erythematosus in Saudi Arabia: morbidity and mortality in a multiethnic population. Lupus 16(11): 908-914.

16. Abid N, Khan AS, Al Otaibi FH (2013) Systemic lupus in Eastern Saudi Arabia. A comparative study. Lupus 22: 1529-1533.

17. Qari FA (2002) Clinical pattern of systemic lupus erythematosus in western Saudi Arabia. Saudi Med J 23(10): 1247-1250.

18. Alzeer AH, Al-Arfaj A, Basha SJ, Alballa S, Al-Wakeel J, et al. (2004) Outcome of patients with systemic lupus erythematosus in intensive care unit. Lupus 13(7): 537-542.

19. Abdel-maksoud MA, AL-Quraishy SA (2018) Autoimmune Diseases and Infections: A Controversial Relationship. Current Immunology Reviews.

20. Al-Rayes H, Al-Swailem R, Arfin M, Sobki S, Rizvi S, et al. (2007) Systemic lupus erythematosus and infections: a retrospective study in Saudis. Lupus 16(9): 755-763.

21. Azhar AS, Awlia OM, Muzaffer MA (2017) Cardiovascular complications in paediatric-onset systemic lupus erythematosus in Saudi Arabian patients. Clin Exp Rheumatol 35(3): 535-541.

22. Alamoudi OS, Attar SM (2015) Pulmonary manifestations in systemic lupus erythematosus: association with disease activity. Respirology 20(3): 474-480.

23. Abid N, Khan AS, Al Otaibi FH (2013) Systemic lupus erythematosus (SLE) in the eastern region of Saudi Arabia. A comparative study. Lupus 22(14): 1529-1533. 
ISSN: 2574-1241

DOI: $10.26717 / B J S T R .2019 .12 .002286$

Mostafa A Abdel Maksoud. Biomed J Sci \& Tech Res

(C) (i) This work is licensed under Creative

Submission Link: https://biomedres.us/submit-manuscript.php

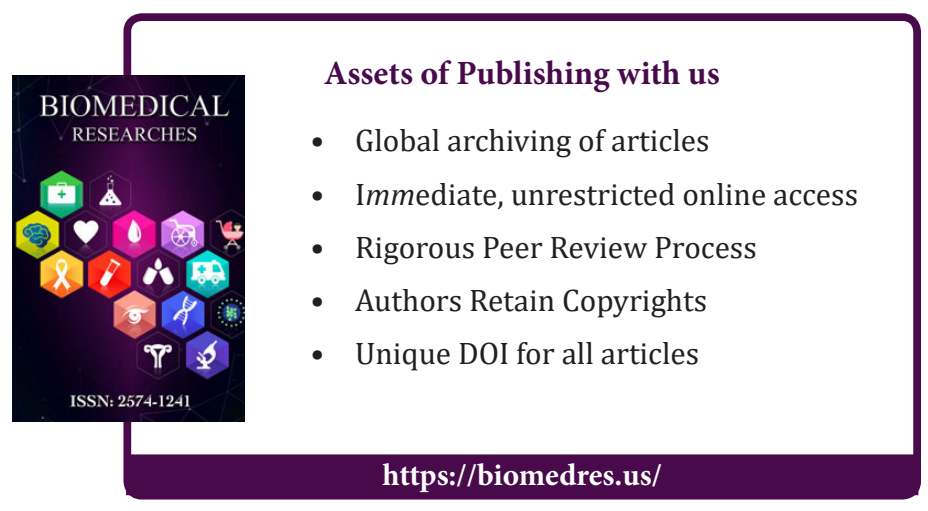

